\title{
Relationships of circulating pregnanolone isomers and their polar conjugates to the status of sex, menstrual cycle, and pregnancy
}

\author{
Radmila Kancheva, Martin Hill, David Cibula, Helena Včeláková, Lyudmila Kancheva, Jana Vrbíková, \\ Tomáš Fait ${ }^{1}$, Antonín Pařízek ${ }^{1}$ and Luboslav Stárka \\ Institute of Endocrinology, Národní tř́́da 8, CZ 11694 Prague 1, Czech Republic \\ ${ }^{1}$ Department of Gynecology and Obstetrics, 1st Medical Faculty, Charles University, Apolinářská 18, CZ 12851 Prague 2, Czech Republic \\ (Requests for offprints should be addressed to M Hill; Email: mhill@endo.cz)
}

\begin{abstract}
Pregnanolone isomers (PIs) and their polar conjugates (PICs) modulate ionotropic receptors such as $\gamma$-aminobutyric acid or pregnane $\mathrm{X}$ receptors. Besides, brain synthesis, PI penetrates the blood-brain barrier. We evaluated the physiological importance of PI respecting the status of sex, menstrual cycle, and pregnancy. Accordingly, circulating levels of allopregnanolone $(\mathrm{P} 3 \alpha 5 \alpha)$, isopregnanolone $(\mathrm{P} 3 \beta 5 \alpha)$, pregnanolone $(\mathrm{P} 3 \alpha 5 \beta)$, epipregnanolone $(\mathrm{P} 3 \beta 5 \beta)$, their polar conjugates, and related steroids were measured in 15 men (M), 15 women in the follicular phase (F), 16 women in the luteal phase (L), and 30 women in the 36th week of gestation (P) using GC-MS. The steroid levels were similar in $\mathrm{M}$ and $\mathrm{F}$, increased about thrice in $\mathrm{L}$ and escalated in $\mathrm{P}$ (38410 times compared with F). The PICs were prevalent over the PIs (16-150 times). Higher ratios of $5 \alpha$-PIC to $5 \alpha$-PI
\end{abstract}

found in $\mathrm{P}$ indicate the more intensive conjugation of $5 \alpha$-PI during pregnancy. This mechanism probably provides for the elimination of neuroinhibitory $\mathrm{P} 3 \alpha 5 \alpha$ in the maternal compartment. Additionally, our result points to a limited sulfation capacity for neuroinhibitory $\mathrm{P} 3 \alpha 5 \beta$ in $\mathrm{P}$. In contrast to the situation in $\mathrm{M}, \mathrm{F}$, and $\mathrm{L}$ where the $\mathrm{P} 3 \alpha 5 \beta \mathrm{C}$ is the most abundant PIC, and $\mathrm{P} 3 \alpha 5 \beta$ is present in minor quantities compared with the $\mathrm{P} 3 \alpha 5 \alpha, \mathrm{P} 3 \alpha 5 \beta$ may acquire physiological importance during pregnancy, contributing to the sustaining thereof. On the other hand, the declining formation of $\mathrm{P} 3 \alpha 5 \beta$ may participate in the initiation of parturition, given the relative abundance of the steroid, its potency to suppress the activity of oxytocin-producing cells and its effectiveness in uterine relaxation.

Journal of Endocrinology (2007) 195, 67-78

\section{Introduction}

Reduced progesterone metabolites, including pregnanolone isomers (PIs) and their polar conjugates (PICs), are efficient neuromodulators. They are effective on neurotransmitter receptors influencing the permeability of ion channels (Majewska 1990). PIs with a hydroxy group in the $3 \alpha-$ position shorten the period of paradoxical sleeping, attenuate the release of acetylcholine in the neocortex and hippocampus, suppress neurogenesis, and deteriorate spatial memory. These effects are provided via modulation of the receptors of type A $\gamma$-aminobutyric acid $\left(\mathrm{GABA}_{\mathrm{A}}-\mathrm{R}\right.$;

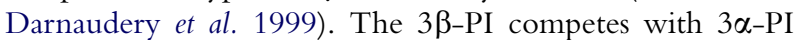
for the binding sites on $\mathrm{GABA}_{\mathrm{A}}-\mathrm{R}$ (Prince \& Simmonds 1992, Wang et al. 2002, Lundgren et al. 2003). Conjugation counteracts the effect of $3 \alpha-\mathrm{PI}$, and further amplifies the antagonistic effect of the $3 \beta-\mathrm{PI}$ on $\mathrm{GABA}_{\mathrm{A}}-\mathrm{R}$. For instance, the $\mathrm{GABA}_{\mathrm{A}}-\mathrm{R}$ inhibiting efficiency of $3 \beta$-hydroxy- $5 \alpha-$ pregnane-20-one sulfate is comparable with the $\mathrm{GABA}_{\mathrm{A}}-\mathrm{R}$ activating effectiveness of allopregnanolone $(\mathrm{P} 3 \alpha 5 \alpha)$. Some reports indicate that in addition to the brain's in situ synthesis, circulating PIs penetrate the blood-brain barrier (Bixo et al.
1997, Corpechot et al. 1997). Although several studies have brought information to light regarding the levels of PI in humans, only a small number have included data regarding the respective polar conjugates (Mickan \& Zander 1979, Hill et al. 2000, Havlikova et al. 2006).

In addition to the action on $\mathrm{GABA}_{\mathrm{A}}-\mathrm{R}$, the $5 \beta$-PI block type $\mathrm{T}$ calcium channels in rat peripheral neurons; these channels play a significant role in pain perception (Todorovic et al. 2004). The 5 3 -PI also binds to nuclear progesterone receptors (Putnam et al. 1991). It has recently been reported that $5 \beta$-PI may act chronically through a mechanism mediated by pregnane $\mathrm{X}$ receptors to regulate uterine contractility (Mitchell et al. 2005). The $5 \alpha$ - and $5 \beta$-PIC are effective as positive and negative modulators of $N$-methylD-aspartate receptors (NMDA-R) respectively (Park-Chung et al. 1997, Weaver et al. 2000). The activation of NMDA-R in hypothalamic magnocellular neuroendocrine cells of the supraoptic nucleus may induce oxytocin production (Pak \& Curras-Collazo 2002), resulting in onset of parturition.

PIs originate from progesterone (Prog) through the action of the ubiquitous $5 \alpha$ - and $5 \beta$-reductase, which is most active in the liver (Ingelman-Sundberg 1976). Both enzymes show 
significant activity in the tissues associated with pregnancy (Lisboa \& Holtermann 1976, Milewich et al. 1979, Sheehan et al. 2005); they catalyze the formation of $5 \alpha-$ and $5 \beta$ dihydroprogesterone $(\mathrm{P} 5 \alpha$ and $\mathrm{P} 5 \beta)$ respectively. The subsequent metabolism of dihydroprogesterone epimers to individual PI is catalyzed by stereospecific $3 \alpha$ - or $3 \beta-$ hydroxysteroid oxidoreductases (Okuda \& Okuda 1984, Melcangi et al. 1994, Corpechot et al. 1997, Ottander et al. 2005). The latter enzyme may be identical to the $3 \beta$ hydroxysteroid dehydrogenase, as indicated in the human placenta study (Dombroski et al. 1997).

PIs, and particularly their polar conjugates, are synthesized in large quantities in the human fetoplacental unit from Prog (Fig. 1; Milewich et al. 1979, Dombroski et al. 1997). As has been documented for $5 \alpha$-PI, the steroids are metabolized to respective 3-oxo-derivatives $(\mathrm{P} 5 \alpha / \beta)$, which are then transported to the maternal compartment via the placenta where they are again converted into PI (Dombroski et al. 1997). The levels of all PI in pregnancy are strikingly higher in comparison with the situation in non-pregnant women (Genazzani et al. 1998, Hill et al. 2000, Luisi et al. 2000, Pearson Murphy et al. 2001, Havlikova et al. 2006).

The aim of this study was to evaluate the physiological impact of endogenous neuroactive PI and PIC in humans, respecting the status of sex, menstrual cycle, and pregnancy. The evaluation was based on the steroid circulating levels and steroid neuromodulating activities reported in the literature. A further objective was to assess inter-group differences in the biosynthesis and metabolism of PI. For these reasons, we measured the circulating levels of all PIs, such as P3 $\alpha 5 \alpha$, isopregnanolone $(\mathrm{P} 3 \beta 5 \alpha$, epiallopregnanolone, isoallopregnanolone), $\mathrm{P} 3 \alpha 5 \beta$, epipregnanolone $(\mathrm{P} 3 \beta 5 \beta)$, and $\mathrm{PIC}$ as

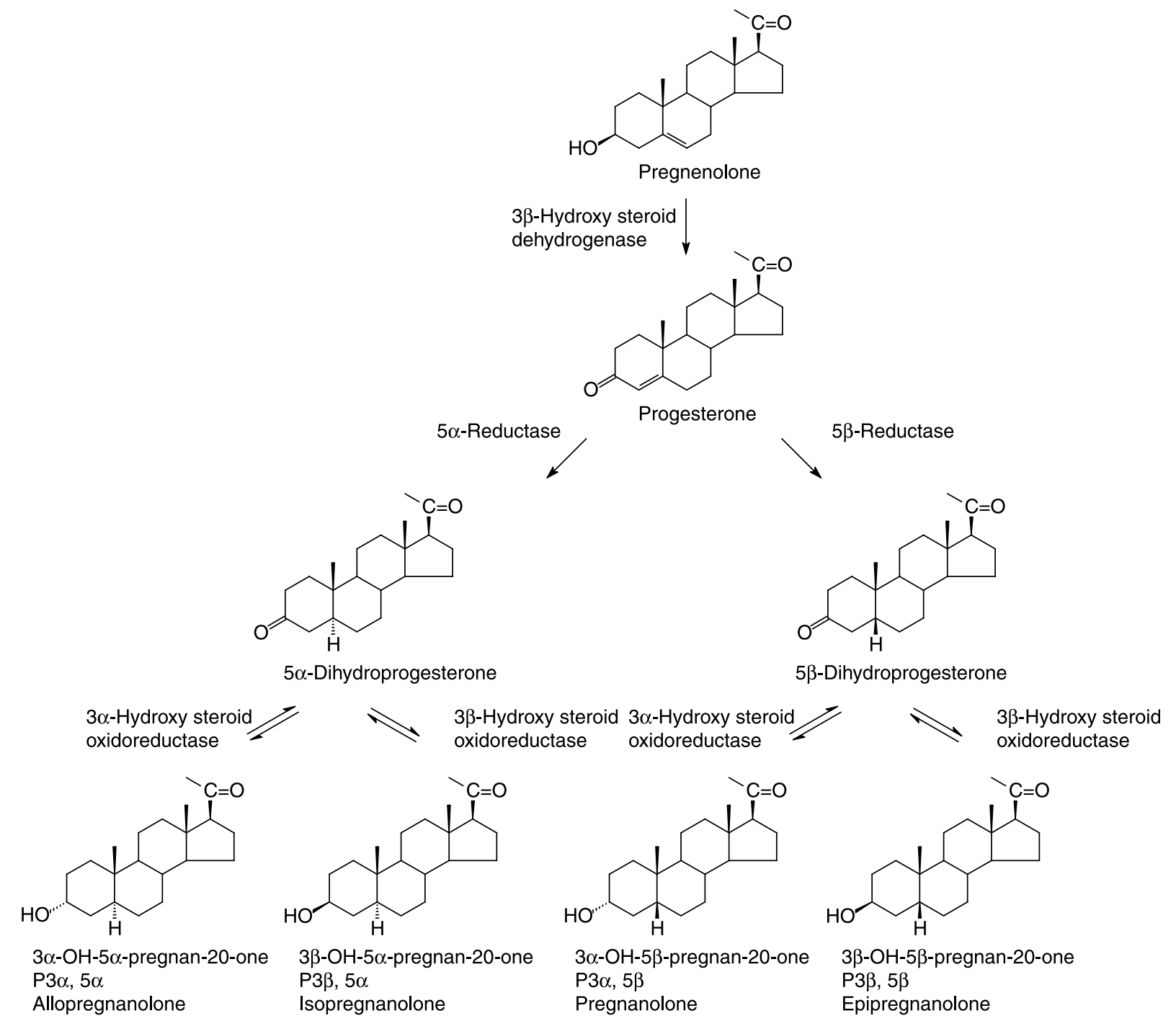

Figure 1 The biosynthesis of pregnanolone isomers. 
conjugates of $\mathrm{P} 3 \alpha 5 \alpha$ (P3 $\alpha 5 \alpha \mathrm{C}), \mathrm{P} 3 \beta 5 \alpha$ (P3 $\beta 5 \alpha \mathrm{C}), \mathrm{P} 3 \alpha 5 \beta$ $(\mathrm{P} 3 \alpha 5 \beta \mathrm{C})$, and $\mathrm{P} 3 \beta 5 \beta(\mathrm{P} 3 \beta 5 \beta \mathrm{C})$ in adult men $(\mathrm{M})$, in women in the follicular (F) and luteal phases (L) of the menstrual cycle (MC), and in women in the 36th week of gestation (P), using GC-MS. In addition, the levels of the respective precursors, free pregnenolone (Preg) and conjugated pregnenolone (PregC), Prog, P5 $\alpha$, and P5 $\beta$ were also quantified.

\section{Materials and Methods}

The circulating levels of all PICs, Preg and PregC were measured in all groups. The levels of all PIs and Prog were measured in F, L, and P. The quantification of P $5 \alpha$ and P5 $\beta$ was limited to $\mathrm{P}$.

\section{Subjects}

The subjects in all groups were Caucasian. The $M$ group consisted of 15 healthy men (16-62 years of age) participating in a study on iodine deficiency in the Czech Republic. The blood from non-pregnant women was collected on the 5th and $22 n d$ days of the MC for the $\mathrm{F}(n=15)$ and $\mathrm{L}(n=16)$ groups respectively. Eleven women were followed in both phases. The 30 pregnant volunteers in the $\mathrm{P}$ group entered the study protocol according to the inclusion and exclusion criteria. The volunteers were enrolled into the study at a single institution between January 2004 and September 2005, according to the following inclusion criteria: age between 18 and 30 years, physiological pregnancy, cephalic presentation of the fetus. The exclusion criteria were as follows: manifestation of pre-eclampsia, chronic medication, anemia, any chronic disease or medication that might influence steroid levels or delivery, premature rupture of membranes, labor induction, or operative delivery in a previous pregnancy. The subjects in all groups used no hormonal treatment for at least 3 months prior to, and during, the trial. All patients enrolled in the study gave signed consent to participate in the study after a full explanation of the purpose and the nature of all the procedures used. The local Ethical Committees of the Institute of Endocrinology and the General Faculty Hospital (both in Prague, Czech Republic) approved the protocol for the study.

\section{Sample collection}

After signing written informed consent, the patients underwent blood sampling from the cubital vein. All blood samples were taken at the same time of day (0900-1200 h, at least $2 \mathrm{~h}$ after waking), under standard conditions (elimination of stress factors, after $15 \mathrm{~min}$ of resting).

Cooled plastic tubes containing $100 \mu \mathrm{l}$ of 5\% EDTA and $50 \mathrm{pl}$ aprotinin (Antilysin from Spofa, Prague, Czech Republic) were used for blood sampling. Plasma was obtained after centrifugation for $5 \mathrm{~min}$ at $2000 \mathrm{~g}$ at $0{ }^{\circ} \mathrm{C}$. The plasma samples were stored at $-20{ }^{\circ} \mathrm{C}$ until analysis.

\section{Steroids and chemicals}

The steroids were purchased from Steraloids (Wilton, NH, USA). The solvents for the extraction and high performance liquid chromatography (HPLC) were of analytical grade, sourced from Merck. The derivatization agent Sylon BFT (bis(trimethylsilyl)-trifluoroacetamide 99\% and trimethylchlorosilane) was purchased from Supelco (Bellefonte, PA, USA).

\section{Instruments}

The GC-MS system was supplied by Shimadzu (Kyoto, Japan). The system consisted of a GC 17A gas chromatograph equipped with automatic flow control, AOC-20 autosampler and for the MS a QP 5050A quadrupole electron-impact detector with a fixed electron voltage of $70 \mathrm{eV}$. A Zebron ZB50 medium polarity capillary column (50\% phenyl $/ 50 \%$ methylpolysiloxane) from Phenomenex (St Torrance, CA, USA) was used for the analysis. The length of the column was $15 \mathrm{~m}$, the internal diameter was $0.25 \mathrm{~mm}$, and the film thickness was $15 \mu \mathrm{m}$.

\section{Preparation of the plasma samples for GC-MS free steroids analysis}

Frozen samples were thawed and $1 \mathrm{ml}$ sample was spiked with $17 \alpha$-estradiol as an internal standard to attain a concentration of $1 \mu \mathrm{g} / \mathrm{ml}$. The spiked sample was extracted with $3 \mathrm{ml}$ diethyl ether. The water phase was kept frozen in a mixture of solid carbon dioxide and ethanol, and the organic phase was decanted into glass tubes and evaporated to dryness. The dry organic phase residue was used for the determination of free steroids. The dry residue was partitioned between $1 \mathrm{ml}$ of $80 \%$ methanol with water and $1 \mathrm{ml} n$-pentane to eliminate the lipids and sterols. The $n$-pentane phase was discarded, while the methanol/water phase containing steroids for analysis was evaporated in a vacuum centrifuge. The samples were prepared twice for further processing using two different derivatization techniques. The first was used for the preparation of steroids with hydroxy groups modified to trimethylsilyl (TMS) derivatives and with intact oxo groups. The second technique produced derivatives with hydroxy groups modified as in the former case but, in addition, with the oxo groups modified by methoxylamine (MOX-TMS derivatives).

The first derivatization technique was used for the quantification of Preg and PIs. The second technique was applied for the measurement of Prog, P5 $\alpha$, and P5 $\beta$.

\section{Sample preparation for the GC-MS analysis of steroid polar conjugates}

The frozen water phase in glass tubes was thawed and mixed with $1 \mathrm{ml}$ methanol. The tubes were centrifuged and 
the $1 \mathrm{ml}$ aliquot of the supernatant was transferred into a glass tube and evaporated in a vacuum centrifuge. The steroid sulfates were hydrolyzed using a method described elsewhere (Dehennin et al. 1996). The hydrolyzed sample was evaporated in a vacuum centrifuge; the dry residue was spiked with $17 \alpha$-estradiol as an internal standard to attain a concentration of $1 \mu \mathrm{g} / \mathrm{ml}$ and further processed in the same way as the free steroids.

\section{Derivatization}

The TMS derivatives of the steroids were prepared using the modified method of Hill et al. (2000), with some of the modifications reported recently (Havlikova et al. 2006). In summary, Sylon B (99\% bis (trimethylsilyl)-trifluroacetamide (BTSFA) $+1 \%$ trimethylchlorosilane (TMCS); $50 \mu \mathrm{l}$ ) was added to the dry residues from plasma, mixed briefly and heated at $90{ }^{\circ} \mathrm{C}$ for $45 \mathrm{~min}$. The derivatization agent was evaporated under a stream of nitrogen. The dry residue was rinsed down with isooctane $(50 \mu \mathrm{l})$ and the mixture was evaporated again. Finally, steroid derivatives were dissolved into $20 \mu$ isooctane, and $4 \mu$ portions were injected into the GC-MS system.

The MOX-TMS derivatives were prepared as follows: $50 \mu \mathrm{l}$ of $2 \%$ solution of MOX-hydrochloride in pyridine were added to the dry residues from plasma, mixed briefly, and heated at $60{ }^{\circ} \mathrm{C}$ for $2 \mathrm{~h}$. The mixture was then evaporated under a stream of nitrogen, before further TMS derivatization proceeded as described previously.

\section{Temperature and pressure gradients for the GC-MS analysis of TMS derivatives}

For the GC-MS analysis of TMS derivatives, the temperature and pressure gradients used were as follows: 1-min high-pressure injection at $120{ }^{\circ} \mathrm{C}$ and $100 \mathrm{kPa}$ followed by a pressure release to $30 \mathrm{kPa}$ and a rapid linear gradient of $40^{\circ} \mathrm{C} / \mathrm{min}$ and $8.5 \mathrm{kPa} / \mathrm{min}$ up to $200{ }^{\circ} \mathrm{C}$ and $49.3 \mathrm{kPa}$, then a slow linear gradient of $2.9^{\circ} \mathrm{C} / \mathrm{min}$ and $0.5 \mathrm{kPa} / \mathrm{min}$ up to $220^{\circ} \mathrm{C}$ and $52.7 \mathrm{kPa}$, a medium linear gradient of $20^{\circ} \mathrm{C} / \mathrm{min}$ and $8 \mathrm{kPa} / \mathrm{min}$ a up to $265^{\circ} \mathrm{C}$ and $70 \mathrm{kPa}$, and a rapid linear gradient of $40^{\circ} \mathrm{C} / \mathrm{min}$ and $10.0 \mathrm{kPa} / \mathrm{min}$ up to $310^{\circ} \mathrm{C}$ and $80.7 \mathrm{kPa}$, followed by a $2-$ min delay. The overall time taken for the analysis was $15 \cdot 3 \mathrm{~min}$.

For the analysis of TMS-MOX derivatives, the following temperature and pressure gradient was used: one minute high-pressure injection at $120^{\circ} \mathrm{C}$ and $100 \mathrm{kPa}$ followed by a pressure release to $30 \mathrm{kPa}$ and a rapid linear gradient of $40{ }^{\circ} \mathrm{C} / \mathrm{min}$ and $8.5 \mathrm{kPa} / \mathrm{min}$ up to $220^{\circ} \mathrm{C}$ and $51 \cdot 0 \mathrm{kPa}$, then a slow linear gradient of $2.9^{\circ} \mathrm{C} / \mathrm{min}$ and $0.5 \mathrm{kPa} / \mathrm{min}$ up to $240^{\circ} \mathrm{C}$ and $54.5 \mathrm{kPa}$, and a rapid linear gradient of $40{ }^{\circ} \mathrm{C} / \mathrm{min}$ and $9 \cdot 0 \mathrm{kPa} / \mathrm{min}$ up to $310^{\circ} \mathrm{C}$ and $70 \mathrm{kPa}$, followed by a $3-$ min delay. The overall time taken for the analysis was $15 \cdot 2 \mathrm{~min}$.

Retention times and effective masses used for the determination of steroids

To exploit the samples, the individual samples were applied three times in independent courses, in each case employing a part of the steroids under investigation. The choices of the steroids measured within the individual courses, as well as the effective masses used for the measurement, were optimized to attain maximum sensitivity at sufficient selectivity. The types of gradients, effective masses for determination and quantification, order numbers of injection, and retention times for the individual steroids are shown in Table 1.

Table 1 Analytical criteria of the method for the multi-component quantification of neuroactive pregnanolone isomers and related steroids

\begin{tabular}{|c|c|c|c|c|c|c|c|}
\hline & Steroid & Form & $\begin{array}{l}\text { Gradient/ } \\
\text { derivatization }\end{array}$ & Injection & $\begin{array}{l}\text { Retention time } \\
\quad(\min )\end{array}$ & $\begin{array}{l}\text { Effective mass } \\
\qquad(\mathrm{m} / \mathrm{z})\end{array}$ & $\begin{array}{l}\text { Detection limit } \\
(\mathrm{nmol} / \mathrm{l}) \\
(\mathrm{mean} \pm \text { s.E.M., } \\
n=5)\end{array}$ \\
\hline \multicolumn{8}{|c|}{ No } \\
\hline 1 & Pregnenolone & $* \mathrm{~F}, \mathrm{C}$ & ${ }^{+} \mathrm{S}$ & 3 & $11 \cdot 592$ & 298,388 & $0 \cdot 058 \pm 0 \cdot 006$ \\
\hline 2 & Progesterone & $\mathrm{F}$ & MS & 1 & $11 \cdot 250,11 \cdot 392$ & $100,341,372$ & $0 \cdot 033 \pm 0 \cdot 004$ \\
\hline 3 & $\begin{array}{l}\text { 3 } \alpha \text {-Dihydroprogesterone } \\
\quad(\mathrm{P} 3 \alpha)\end{array}$ & $\mathrm{F}$ & MS & 1 & $10 \cdot 975,11 \cdot 008$ & 288,343 & $0 \cdot 020 \pm 0 \cdot 002$ \\
\hline 5 & $\begin{array}{l}\text { Allopregnanolone } \\
\quad(\mathrm{P} 3 \alpha 5 \alpha)\end{array}$ & $\mathrm{F}, \mathrm{C}$ & $\mathrm{S}$ & 1 & $10 \cdot 758$ & $285,300,375$ & $0 \cdot 028 \pm 0 \cdot 004$ \\
\hline 6 & $\begin{array}{l}\text { Isopregnanolone } \\
\quad(\mathrm{P} 3 \beta 5 \alpha)\end{array}$ & $\mathrm{F}, \mathrm{C}$ & $\mathrm{S}$ & 1 & $11 \cdot 563$ & $285,300,375$ & $0 \cdot 030 \pm 0 \cdot 004$ \\
\hline 7 & Pregnanolone (P3 $\alpha 5 \beta)$ & $\mathrm{F}, \mathrm{C}$ & $\mathrm{S}$ & 1 & $10 \cdot 950$ & $285,300,375$ & $0 \cdot 043 \pm 0 \cdot 006$ \\
\hline
\end{tabular}

${ }^{*} \mathrm{~F}$, free steroid, C, conjugated steroid; ${ }^{\dagger} \mathrm{S}$, trimethylsilyl derivatives, MS, methoxyamine-trimethylsilyl derivatives. 
Statistical analysis of the data

The data showed mostly non-Gaussian distribution and non-constant variance. To evaluate changes in the steroid levels and steroid ratios, a robust Kruskal-Wallis ANOVA was used with group as the factor. Multiple testing was handled by Kruskal-Wallis multiple comparisons to evaluate differences between the individual groups. The relationships between the steroids were evaluated using Spearman's correlations and partial Spearman's correlations. Given the sufficient number of pairs, the partial Spearman's correlations in pregnant women were adjusted to constant levels of all steroids included in a correlation matrix, except the pair under investigation. Statistical computations were performed using NCSS 2002 statistical software from Number Cruncher Statistical Systems (Kaysville, UT, USA).

\section{Results}

\section{Identification and quantification of the steroids}

The steroids separated well from each other and from the background. As demonstrated in Table 1, the selectivity and sensitivity were sufficient for quantification of all of the investigated steroids. In terms of reproducibility, the inter-assay coefficient of variance did not exceed $10 \%$ for any steroid.

\section{Steroid levels}

The levels of free and conjugated steroids are shown in Figs 2-4. The levels of P3 $\alpha 5 \alpha$ (Fig. 3A) increased in the sequence $\mathrm{M}, \mathrm{F}, \mathrm{L}$, and $\mathrm{P}$. All inter-group differences except the differences between $\mathrm{M}$ and $\mathrm{F}$ were significant. A similar situation was found in all PIs except the missing data for the $M$ group in $5 \beta$-PI. The PIC showed a similar trend. The levels in both PI and PIC in P were about two orders of magnitude higher than those found in F or M (Figs 3 and 4).

\section{Ratios of conjugates to free steroids}

Both $5 \alpha$-PI exhibited higher conjugate to free steroid ratios for $\mathrm{M}$ and $\mathrm{P}$ (which did not differ from each other) when compared with $\mathrm{F}$ and $\mathrm{L}$ (Fig. 5A and B). In the ratios of $\mathrm{P} 3 \beta 5 \alpha \mathrm{C}$ to $\mathrm{P} 3 \beta 5 \alpha$, however, the differences between $\mathrm{M}$ and the groups of non-pregnant women did not reach significance (Fig. 5B). In contrast to the situation in $5 \alpha$-PI, the ratio of $\mathrm{P} 3 \alpha 5 \beta \mathrm{C}$ to $\mathrm{P} 3 \alpha 5 \beta$ showed decreasing trend in the sequence F, L, and P. Significantly lower value of the ratio was found in $\mathrm{P}$ when compared with the values in $F$ and $L$ (Fig. 5C). The ratios of $\mathrm{P} 3 \beta 5 \beta \mathrm{C}$ to $\mathrm{P} 3 \beta 5 \beta$ did not exhibit any betweengroup difference (Fig. 5D).
Ratios of $3 \alpha$-to $3 \beta$-isomers

As demonstrated in Fig. 6A, the $F$ and $L$ groups showed more than two times lower values for the ratio than was the case for the $\mathrm{P}$ group. The respective differences in the conjugates were much less pronounced (Fig. 6B); nevertheless, the ratios for $P$ still exhibited the highest values.

\section{Ratios of the $5 \alpha$ - to $5 \beta$-isomers}

The ratios of $5 \alpha$-PI to $5 \beta$-PI showed higher values for $F$ and $L$ groups when compared with $\mathrm{P}$ group (Fig. 7A). The situation was different in PIC, where the ratios were significantly higher in $\mathrm{L}$ and even more elevated in the $\mathrm{P}$ group when compared with the values found in $\mathrm{M}$ and $\mathrm{F}$ groups that did not differ from each other (Fig. 7B).

\section{Correlations between conjugated and unconjugated steroids in women}

In the $\mathrm{F}$ group, the only significant correlation between conjugated and free PI was found for the P3 $\beta 5 \beta(r=0.536$, $P=0 \cdot 040, n=15)$. The symbols $r, P$, and $n$ symbolize the Spearman's correlation coefficient, its statistical significance, and number of pairs under investigation respectively. In $L$ group, the P3 $\alpha 5 \alpha$ significantly correlated with the P3 $\alpha 5 \alpha \mathrm{C}$ $(r=0.753, P=0.001, n=16)$ and $\mathrm{P} 3 \beta 5 \alpha$ with $\mathrm{P} 3 \beta 5 \alpha \mathrm{C}$ $(r=0.585, P=0 \cdot 017, n=16)$. The respective correlations for the $\mathrm{P} 3 \alpha 5 \beta(r=0 \cdot 409, P=0 \cdot 116, n=16)$ and $\mathrm{P} 3 \beta 5 \beta$ $(r=0 \cdot 338, P=0 \cdot 200, n=16)$ did not reach significance. In $\mathrm{P}$ group, the correlations between conjugated and free PI reached significance for the P3 $\beta 5 \alpha(r=0.528, P=0.004$, $n=28)$ and for the P3 $\beta 5 \beta(r=0 \cdot 431, P=0 \cdot 022, n=28)$.

\section{Correlations between $3 \alpha$ - and $3 \beta$-isomers}

Significant correlations between $3 \alpha$ - and $3 \beta$-PI were mostly found within all groups for both $5 \alpha$ - and $5 \beta-\mathrm{PI}$, except for the missing data for $5 \beta-\mathrm{PI}$ in men. P $3 \alpha 5 \alpha$ and $\mathrm{P} 3 \beta 5 \alpha$ significantly correlated in $F(r=0.693, P=0 \cdot 040, n=15), L$ $(r=0.965, P<0.001, n=16)$, and $P(r=0.695, P<0.001$, $n=30)$. The correlation between the $\mathrm{P} 3 \alpha 5 \alpha \mathrm{C}$ and $\mathrm{P} 3 \beta 5 \alpha \mathrm{C}$ did not reach significance in the $F$ group $(r=0 \cdot 275$, $P=0 \cdot 321, n=15)$ but strongly correlated in $L(r=0 \cdot 918$, $P<0.001, n=16)$ and $P(r=0.660, P<0.001, n=28)$. $\mathrm{P} 3 \alpha 5 \beta$ and $\mathrm{P} 3 \beta 5 \beta$ significantly correlated in $F(r=0 \cdot 764$, $P=0 \cdot 001, n=15), L(r=0.594, P=0 \cdot 015, n=16)$, and $P$ $(r=0.649, \quad P<0.001, n=30)$. Similarly, P3 $\alpha 5 \beta C$ and P3 $\beta 5 \beta C$ significantly correlated in $F(r=0.543, P=0.037$, $n=15), L(r=0 \cdot 600, P=0 \cdot 014, n=16)$, and $P(r=0 \cdot 812$, $P<0 \cdot 001, n=28)$.

\section{Correlations between PI and progesterone}

The correlation between P $3 \alpha 5 \alpha$ and Prog did not reach significance in $F(r=0 \cdot 434, P=0 \cdot 106, n=15)$ but the steroids 
A

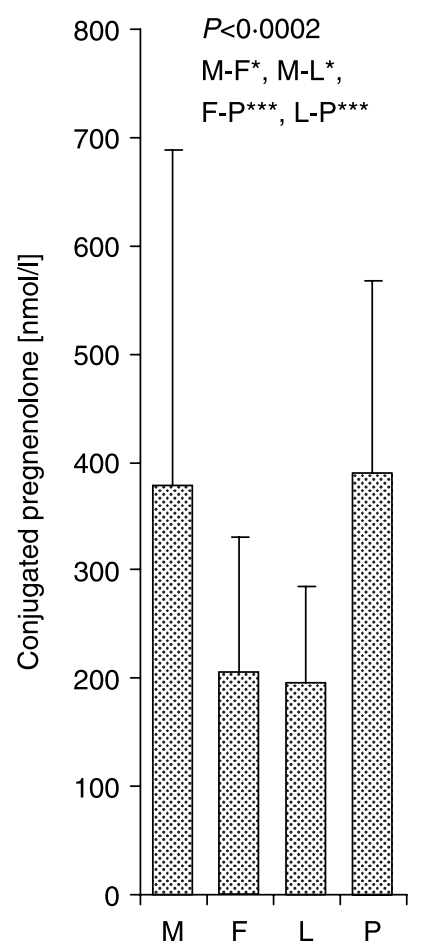

B

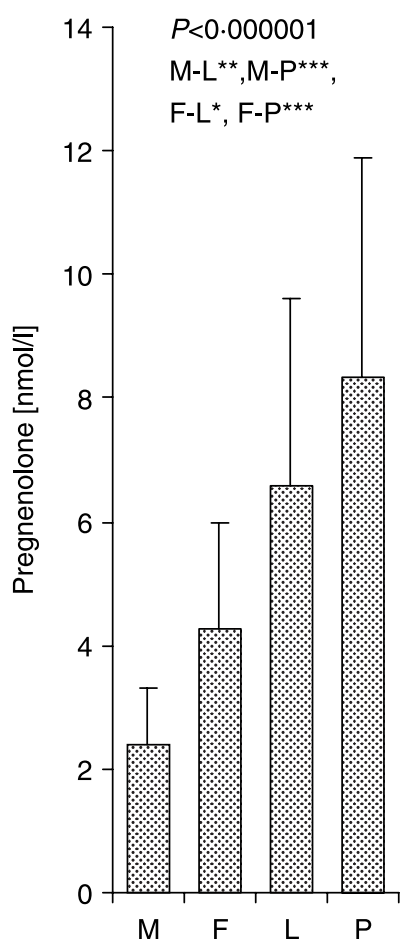

C

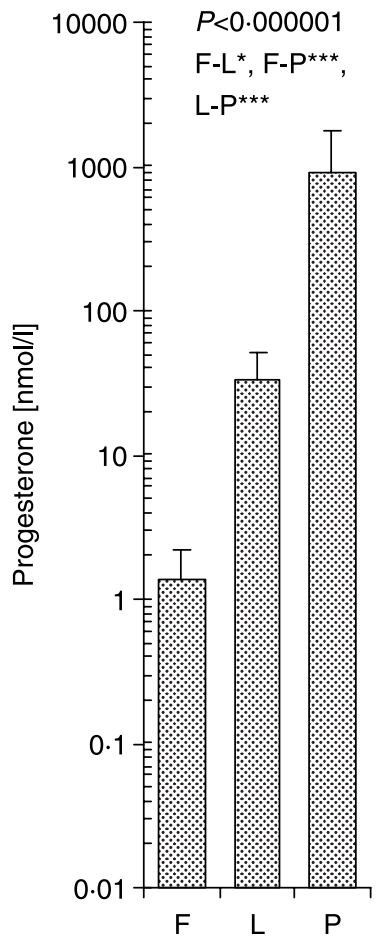

Figure 2 Levels of polar conjugates of pregnenolone (A), unconjugated pregnenolone (B), and progesterone (C) in 15 adult men $(M), 15$ women in follicular phase of menstrual cycle (F), 16 women in the luteal phase (L), and 30 women in the 36 th week of gestation $(\mathrm{P})$. Bars with error bars represent group means with s.D.s. Owing to skewed data distribution and non-constant variance, the between-group were evaluated using robust Kruskal-Wallis ANOVA followed by Kruskal-Wallis multiple comparisons. The significance of ANOVA model is shown in the first line of the embedded table, while significant inter-group differences as found by the multiple comparisons $(P<0 \cdot 05)$ are shown in the further lines of this table $\left({ }^{*} P<0 \cdot 05,{ }^{* *} P<0 \cdot 01\right.$, $* * * P<0 \cdot 001)$.

strongly correlated in $L(r=0 \cdot 744, P<0 \cdot 001, n=16)$ and $P$ $(r=0 \cdot 771, P<0 \cdot 001, n=29)$. P3 $35 \alpha$ and Prog significantly correlated in $\mathrm{F}(r=0.523, P=0 \cdot 045, n=15), L(r=0 \cdot 788$, $P<0.001, n=16)$, and a weaker but still significant correlation was found in $P(r=0 \cdot 399, P=0 \cdot 032, n=16)$. The P $3 \alpha 5 \beta$ and Prog strongly correlated in $L(r=0 \cdot 818$, $P<0.001, n=16)$ but not in $F(r=-0.183, P=0.514$, $n=15)$ and $\mathrm{P}(r=0 \cdot 348, P=0 \cdot 434, n=29)$. Like the $\mathrm{P} 3 \alpha 5 \beta$, $\mathrm{P} 3 \beta 5 \beta$ did not correlate with Prog in $F(r=-0 \cdot 219$, $P=0 \cdot 065, n=15)$, but the significant correlations were found in $L(r=0.500, P=0 \cdot 049, n=16)$ and $P(r=0 \cdot 710$, $P<0 \cdot 001, n=29)$.

\section{Relationships between steroids}

PregC negatively correlated with the $5 \alpha$-PI in men, attaining significance for $\mathrm{P} 3 \alpha 5 \alpha(r=-0 \cdot 709, P<0 \cdot 022, n=10)$ but not for $\mathrm{P} 3 \beta 5 \alpha(r=-0 \cdot 503, P<0 \cdot 14, n=10)$. The subsequent partial correlations confirmed a negative borderline association between PregC and $\mathrm{P} 3 \alpha 5 \alpha(r=-0.633, P<0 \cdot 1$, $n=10$, adjusted to constant Preg and P3 $\beta 5 \alpha$ ), but showed no direct relationship between PregC and P3 $\beta 5 \alpha(r=0 \cdot 260$, $P=0 \cdot 504, n=10$, adjusted to constant Preg and P3 $\alpha 5 \alpha)$. Both pair correlations and partial correlations identified a strong positive relationship between $\mathrm{P} 3 \alpha 5 \alpha$ and $\mathrm{P} 3 \beta 5 \alpha(r=$ $0.707, P<0.003, n=15)$ and $(r=0.758, P<, P<0.003$, $n=15$, adjusted to constant PregC and Preg).

\section{Discussion}

The levels of Preg, PregC, all PIs, and PICs in women in the 36th week of gestation and in non-pregnant women in both phases of the MC were quantified. In addition, the levels of the Preg, PregC, $5 \alpha$-PI as well as the concentrations of all PICs were measured in men (Figs 2-4). The results clearly showed the need to differentiate among M, F, L, and P groups when evaluating changes of circulating PI in connection with various pathologies. The distinctive effects of PI are to be expected in pregnancy due to persistently elevated levels of $3 \alpha-P I$, resulting in a decreased affinity of $G_{A B A}-R$ for 

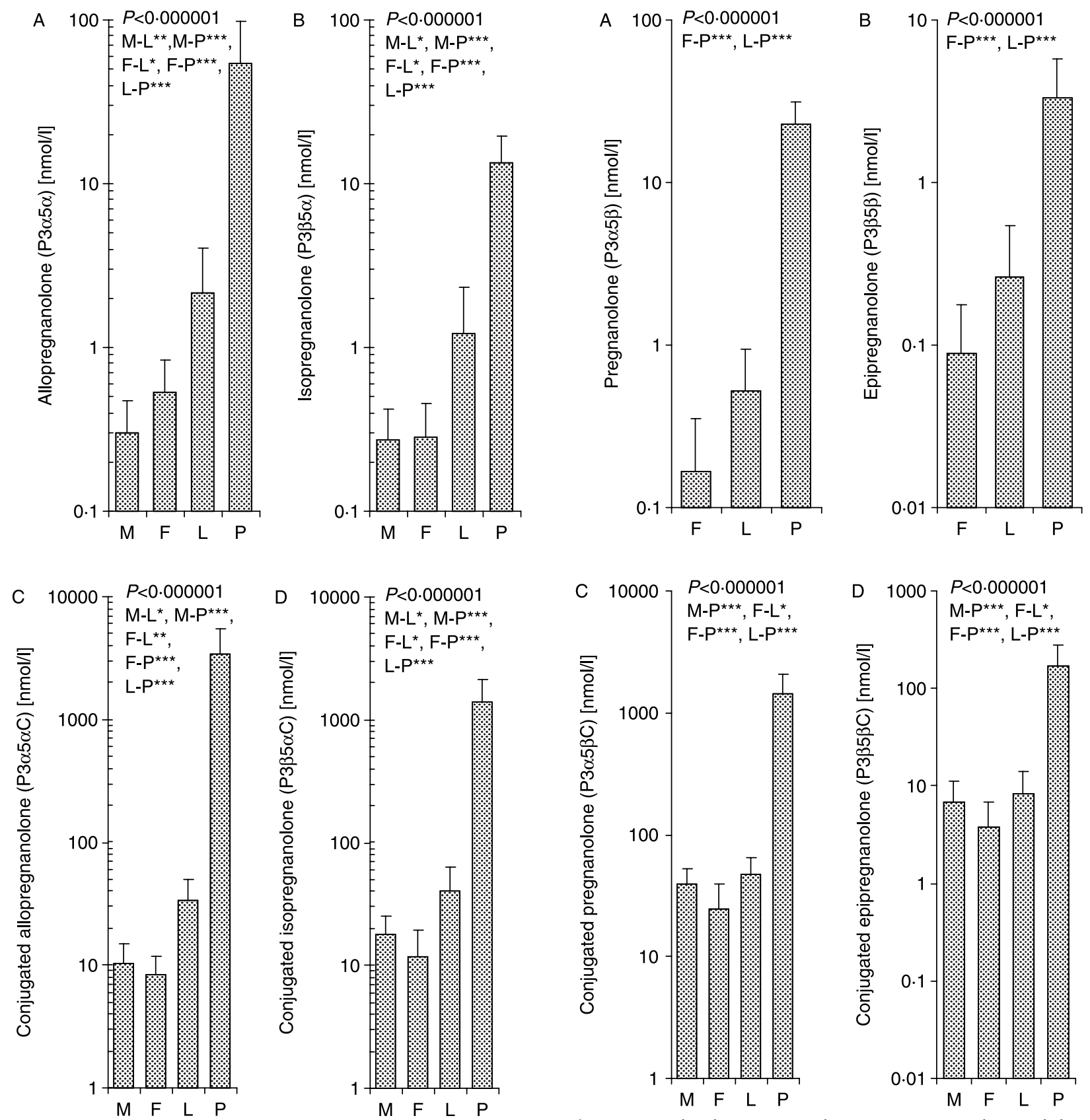

Figure 3 Levels of $5 \alpha$-pregnanolone isomers (A and B) and their polar conjugates $(C$ and $D$ ), in 15 adult men $(M)$ (only ten men were examined for conjugated steroids), 15 women in follicular phase of menstrual cycle $(\mathrm{F}), 16$ women in the luteal phase $(\mathrm{L})$, and 30 women in the 36 th week of gestation $(\mathrm{P})$. The drawings and symbols are the same as for Fig. 2.

these neuroactive steroids either due to the changed expression of the receptor subunits and/or as a result of the changed phosphorylation status of the specific sites on the $\mathrm{GABA}_{\mathrm{A}}-\mathrm{R}$ (Leng \& Russell 1999, Brussaard et al. 2000, Koksma et al. 2003).

Figure 4 Levels of $5 \beta$-pregnanolone isomers (A and B) and their polar conjugates $(C$ and $D)$, in 15 adult men $(M)$ (only ten men were examined for conjugated steroids), 15 women in follicular phase of menstrual cycle $(\mathrm{F}), 16$ women in the luteal phase $(\mathrm{L})$, and 30 women in the 36 th week of gestation $(\mathrm{P})$. The drawings and symbols are the same as for Fig. 2.

In men and to a large extent in women in the follicular phase, the most important role of adrenal activity and in situ brain synthesis of PI can be expected in the overall balance of PI (Fig. 8A and B). Our data suggest that the production of PI in men may depend on sulfatase activity. In M group, PregC 

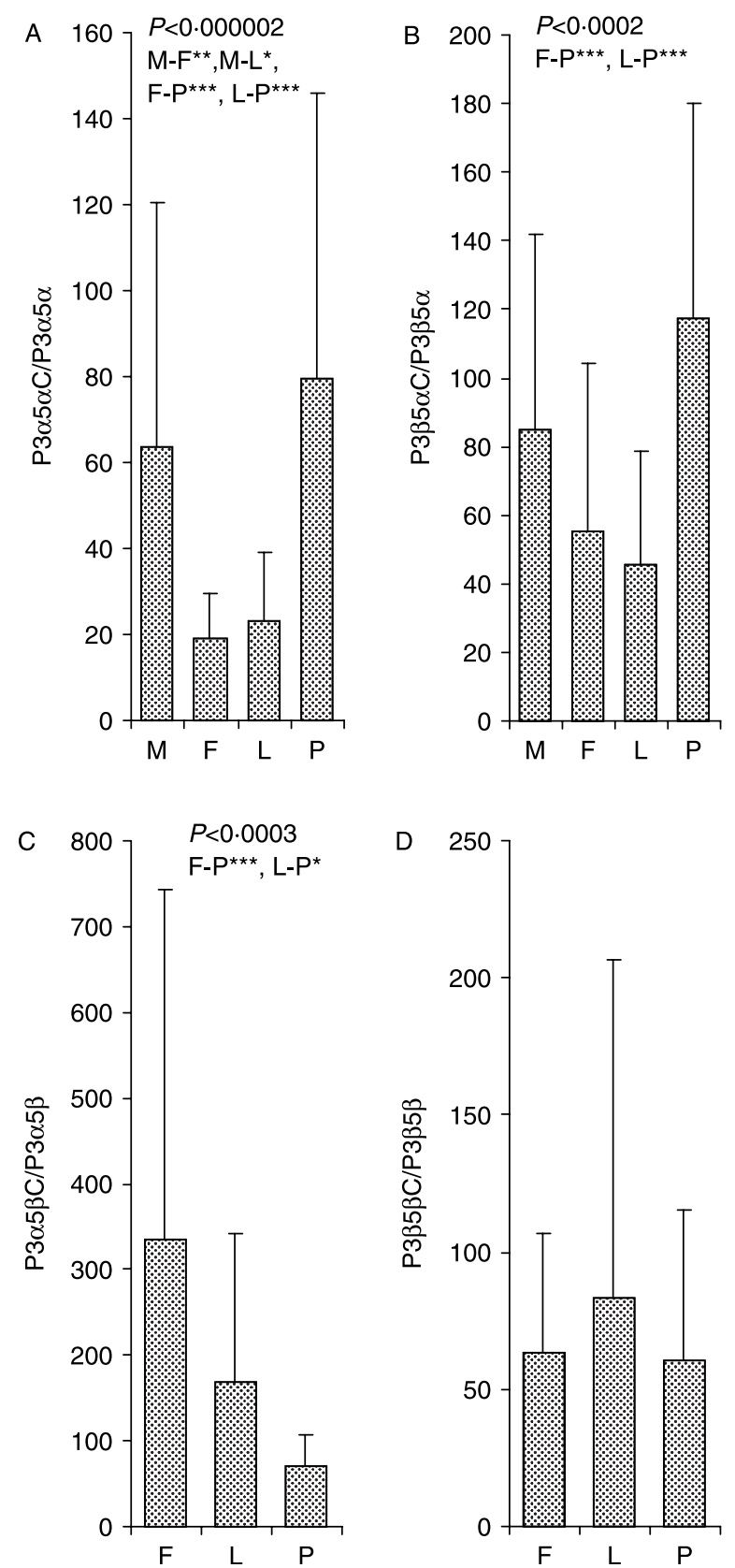

Figure 5 Ratios of polar conjugates to unconjugated steroids for allopregnanolone $(\mathrm{P} 3 \alpha 5 \alpha ; \mathrm{A})$, isopregnanolone $(\mathrm{P} 3 \beta 5 \alpha ; \mathrm{B})$, pregnanolone (P3 $\alpha 5 \alpha ; \mathrm{C})$, and epipregnanolone (P3 $\beta 5 \beta ; \mathrm{D})$, in the groups of 15 women in the follicular $(F)$ and 16 women in the luteal (L) phases of the menstrual cycle, and 30 women in the 36th week of gestation $(P)$. The letter $C$ at the end of the aforementioned abbreviations denotes conjugated steroids. The remaining drawings and symbols are the same as for Fig. 2 .

correlated with $\mathrm{P} 3 \alpha 5 \alpha$. This finding, like the increased ratios of PIC to PI, may indicate that lower sulfatase activity could be associated with a lower amount of Preg as the primary substrate for enzymes catalyzing the formation of Prog and PI.
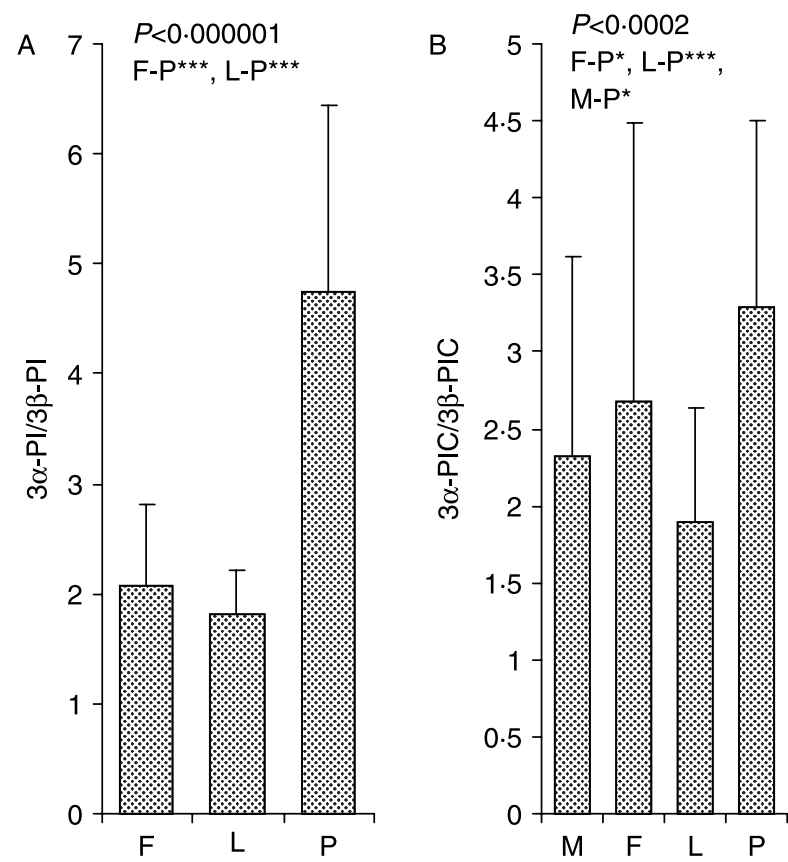

Figure 6 Ratios of the sum of unconjugated pregnenolone isomers with a hydroxy group in the $3 \alpha$-position $(3 \alpha-\mathrm{Pl} / 3 \beta-\mathrm{Pl} ; \mathrm{A})$ to the sum of unconjugated pregnenolone isomers with a hydroxy group in the $3 \beta$-position and the ratio of the steroid polar conjugates $(3 \alpha-\mathrm{PIC} / 3 \beta-\mathrm{PIC} ; \mathrm{B})$, in the groups of adult men $(\mathrm{M})$, women in the follicular (F) and luteal (L) phases of the menstrual cycle, and women in the 36 th week of gestation $(P)$. The drawing and symbols are the same as for Fig. 2.

The partial correlations confirmed the negative borderline association between PregC and $\mathrm{P} 3 \alpha 5 \alpha$ but showed no relationship between PregC and P3 $\beta 5 \alpha$. As expected, both pair and partial correlations found a strong positive relationship between $\mathrm{P} 3 \alpha 5 \alpha$ and $\mathrm{P} 3 \beta 5 \alpha$. Given the aforementioned results, the major metabolic pathway in adult men may be expected in the sequence PregC $\rightarrow \operatorname{Preg} \rightarrow \operatorname{Prog} \rightarrow$ $\mathrm{P} 5 \alpha \rightarrow \mathrm{P} 3 \alpha 5 \alpha \rightarrow \mathrm{P} 3 \beta 5 \alpha$.

Women in the luteal phase and early pregnancy produce the bulk of the PI in the corpus luteum (Ottander et al. 2005) PI (Fig. 8C).

After the luteo-placental shift, the primary precursor of the PI, PregS, originates almost entirely from the fetal zone of the fetal adrenal (Fig. 8D). PregS is transported into the placenta by circulation, being converted to Preg, Prog, and P $5 \alpha / \beta$, in sequence. The $\mathrm{P} 5 \alpha$ and possibly also the $\mathrm{P} 5 \beta$ penetrate into the maternal compartment, being further metabolized to PI and PIC (Dombroski et al. 1997).

While the $5 \alpha$-PI showed higher ratios of conjugates to the free steroids (Fig. 5A and $\mathrm{B}$ ) in $\mathrm{P}$ group, the respective ratios were similar in $\mathrm{F}, \mathrm{L}$, and $\mathrm{P}$ groups for $\mathrm{P} 3 \beta 5 \beta$ (Fig. $5 \mathrm{D}$ ) and showed a significantly decreasing trend for $\mathrm{P} 3 \alpha 5 \beta$ in sequence F, L, and P (Fig. 5C) groups. It is evident that the groups with low Prog production exhibited very low concentrations of unconjugated $\mathrm{P} 3 \alpha 5 \beta$. In these subjects, the $\mathrm{P} 3 \alpha 5 \beta$ may be 

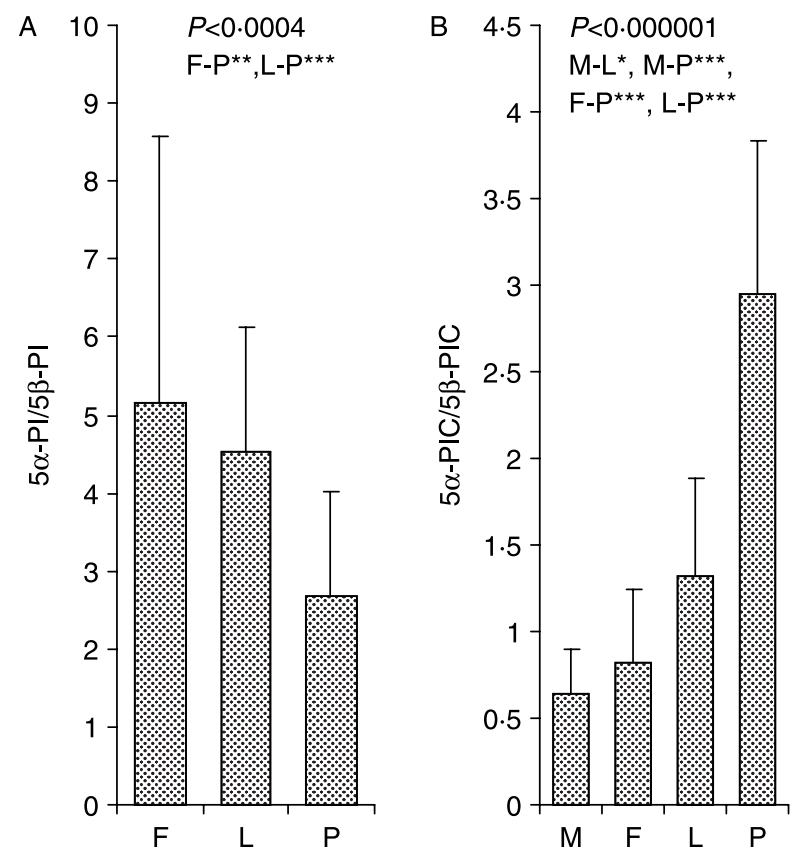

Figure 7 Ratios of the sum of unconjugated pregnenolone isomers with hydrogen in the $5 \alpha$-position $(5 \alpha-\mathrm{Pl} / 5 \beta-\mathrm{Pl} ; \mathrm{A})$ to the sum of unconjugated pregnenolone isomers with hydrogen in the $5 \beta$ position and the ratio of the steroid polar conjugates $(5 \alpha-\mathrm{PIC} / 5 \beta$ PIC; B), in the groups of adult men (M), women in the follicular (F) and luteal (L) phases of the menstrual cycle, and women in the 36th week of gestation $(\mathrm{P})$. The drawings and symbols are the same as for Fig. 2.

rapidly metabolized to its conjugates. Alternatively, in $\mathrm{L}$ and $\mathrm{P}$ groups, the conjugation capacity for $\mathrm{P} 3 \alpha 5 \beta$ appears to be limited. The increased conjugation of $5 \alpha$-PI probably diminishes the difference between the $\mathrm{P} 3 \alpha 5 \alpha$ and $\mathrm{P} 3 \alpha 5 \beta$ levels in pregnant women and may also regulate the proportions between neuroinhibiting $\mathrm{P} 3 \alpha 5 \alpha$ and counteracting $5 \alpha$-PIC. On the $\mathrm{GABA}_{\mathrm{A}}-\mathrm{R}$, the $\mathrm{P} 3 \beta 5 \alpha \mathrm{C}$ exerts about $10 \%$ efficiency when compared with the effect of P3 $35 \alpha$. However, P3 $\beta 5 \alpha \mathrm{C}$ operates in the opposite way (ParkChung et al. 1999). In all groups, the levels of all PICs exceed the levels of PI from one to more than two orders of magnitude. The situation in the proximity of the active sites may not necessarily reflect the conditions in the circulation, however. The conjugation may also hinder the transport of PI across the blood-brain barrier, but in the periphery, it probably facilitates the transport of significant amounts of neuroactive steroids by circulation to the sites where they take effect.

To evaluate the inter-group differences in the relative amount of $3 \alpha$-PI positively modulating $\mathrm{GABA}_{\mathrm{A}}-\mathrm{R}$ and $3 \beta-\mathrm{PI}$ being inactive but competing with the former PI on the receptors, the ratios of the sum of the $3 \alpha-\mathrm{PI}$ to the sum of $3 \beta-$ PI were evaluated. As demonstrated in Fig. 6A, the $F$ and $L$ groups displayed more than two times lower values for the ratio than the $P$ group. This means that as regards the free steroids, the circulating positive $\mathrm{GABA}_{\mathrm{A}}-\mathrm{R}$ modulators are more manifestly prevalent in pregnancy over their inactive competitors on the $\mathrm{GABA}_{\mathrm{A}}-\mathrm{R}$. The respective differences in conjugates were much less pronounced (Fig. 6B).

Strong correlations between $3 \alpha$ - and $3 \beta$-PI that were found within all groups illustrate an uncomplicated, reversible oxidoreductive switch between the $3 \alpha$ - and $3 \beta$-PI via the 3 -oxo-intermediate product in all groups. These metabolic steps converting neuroinhibiting $3 \alpha$-PI to $3 \beta$-PI which competes with the $3 \alpha$-PI on $G_{A B A}-R$, as well as the sulfoconjugation of the $\mathrm{PI}$-forming products operating on the $\mathrm{GABA}_{\mathrm{A}}-\mathrm{R}$ in an opposite way to free $3 \alpha-\mathrm{PI}$, may be of great importance. It is known that $\mathrm{P} 3 \alpha 5 \alpha$ dosage in animals or humans usually results in a weaker response than expected in consideration of the results of in vitro experiments. P $3 \alpha 5 \alpha$ dosage eventuates in a bell-shaped response. At lower concentrations, $\mathrm{P} 3 \alpha 5 \alpha$ paradoxically acts as neurostimulant showing a neuroinhibiting effect as late as at levels comparable with the concentrations common in pregnancy (Backstrom et al. 2003). Moreover, one of the neuroinhibiting PIs, P3 $\alpha 5 \beta$ is an unstable substance with a short half-life in the human organism (Carl et al. 1994). P3 $\alpha 5 \beta$ is identical to a short-term central anesthetic eltanolone that has previously been tested in pharmacological studies (Hering et al. 1996). Given the data from this study, it seems likely that the instability of $\mathrm{P} 3 \alpha 5 \beta$ is strongly associated with the reversible metabolic steps outlined above.

The initiation of human parturition represents a complex system involving various factors and multiple, interconnected feedback loops (Nathanielsz 1998). Several mechanisms have been suggested to explain the primary impulse for parturition. Some of them involve significantly decreasing the placental synthesis of Prog, while at the same time increasing estradiol production before the onset of parturition (Nathanielsz 1998, Wu et al. 2004). In contrast to non-primate species, progesterone levels in human maternal serum do not change markedly around parturition, while estradiol levels escalate up to labor, as in other mammals (Mathur et al. 1980). Despite the number of mechanism suggested (McLean \& Smith 2001, Patel et al. 2003, Condon et al. 2004, Mesiano 2004), our knowledge regarding the primary impulse for the human parturition remains inadequate. The role of neuroactive reduced progesterone metabolites - and particularly the most abundant of them, PIs - in the timing of human parturition is still unclear, despite studies reporting their major effects in other mammals (Brussaard et al. 1997, 2000). In rats, decreasing allopregnanolone levels just before labor induce a positive feedback loop in oxytocin production, resulting in a rapid delivery (Brussaard et al. 1997, 2000). The latter substance brings the $\mathrm{GABA}_{\mathrm{A}}-\mathrm{R}$ from a neurosteroidsensitive mode toward a condition in which the receptors are not sensitive (Koksma et al. 2003), via a shift in the balance between the activities of endogenous Ser/Thr phosphatase and protein kinase C (Koksma et al. 2003). Given all the foregoing, it seems likely that changing the biosynthesis of PIs 
A Men

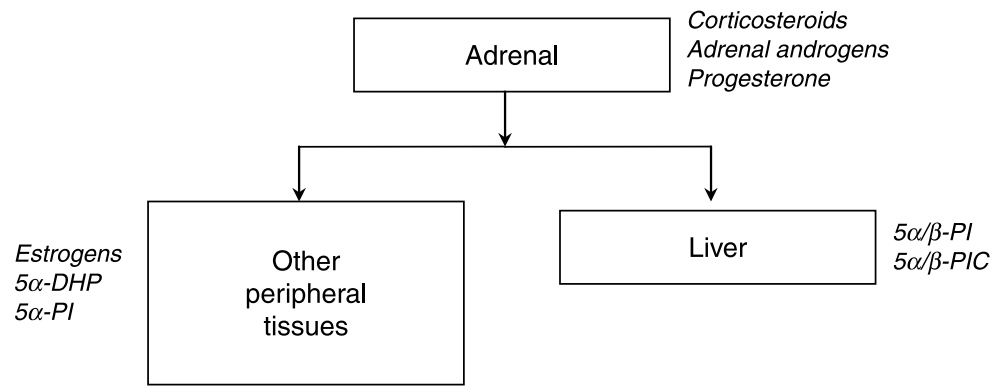

B

Follicular phase

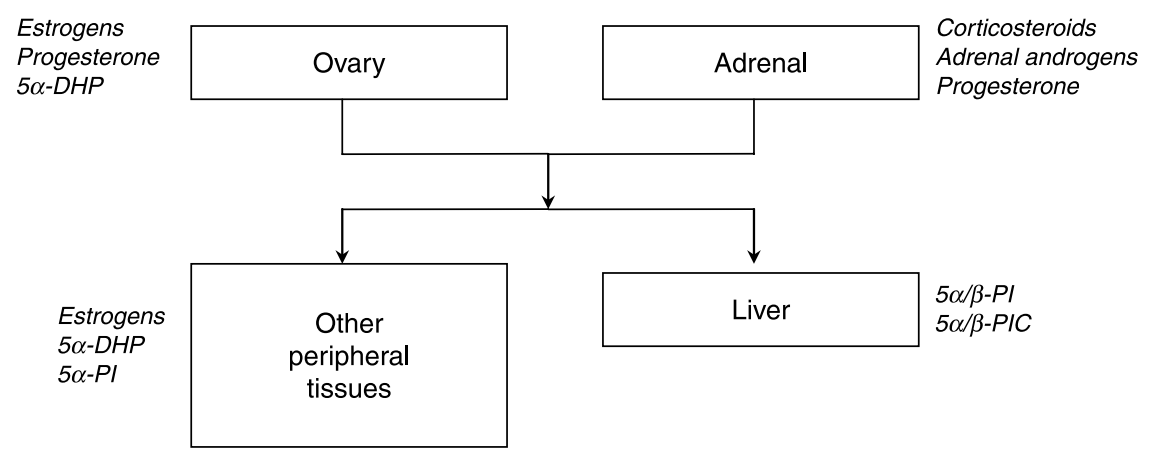

C Luteal phase

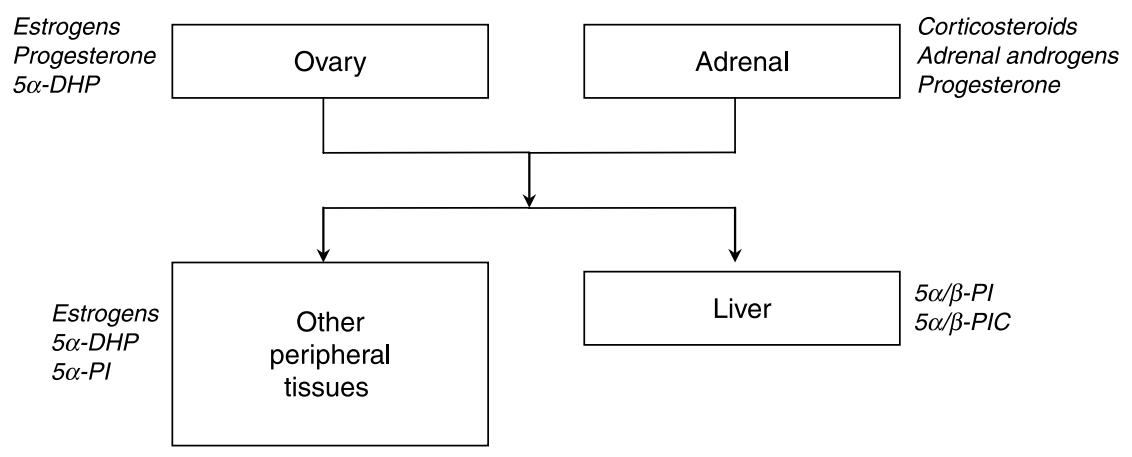

D Pregnancy

Fetal adrenal

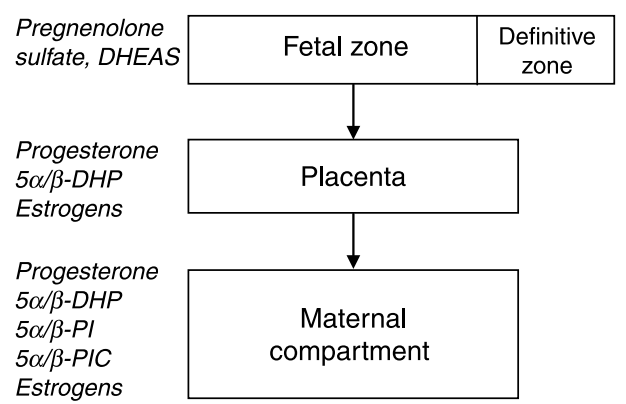

Figure 8 Biosynthesis of pregnanolone isomers in men (A), women in the follicular and luteal phase of menstrual cycle respectively ( $B$ and $C$ respectively) and in pregnant women (D). 
could influence the onset of labor. Moreover, unconjugated $5 \beta$-pregnane steroids cause rapid uterine relaxation through a pregnane receptor X-mediated mechanism (Mitchell et al. $2005)$. In this respect, the increased proportion of the $5 \beta$-PI demonstrated in Fig. 7A allows speculation regarding the pregnancy sustaining role of pregnanolone. The weakening activity of $5 \beta$-reductase (Sheehan et al. 2005) as well as the declining levels of reduced $5 \beta$-pregnane steroids near term, further supports this hypothesis (Gilbert Evans et al. 2005). The results obtained in this study suggest that the sulfation of $\mathrm{P} 3 \beta 5 \alpha$ is an important metabolic step contributing to progesterone catabolism in the maternal compartment. Using partial correlations with adjustment to constant levels of all steroids in the correlation matrix, except for the pair under investigation, $\mathrm{P} 3 \beta 5 \alpha \mathrm{C}$ in pregnant women negatively correlated with Prog $(r=-0.512, P=0.043$, $n=27)$. The negative partial correlation between Prog and P3 $\alpha 5 \beta(r=-0.548, P=0 \cdot 019, n=29)$ indicates that a significant amount of Prog may be also metabolized via the $5 \beta$-pathway.

In conclusion, the circulating levels of PI and PIC showed similar values for the $M$ and $F$, while significantly higher levels of the steroids were found in L, and prominently higher concentrations were observed in P. The neuroactivating PICs were strikingly prevalent over the neuroinhibitory $3 \alpha-\mathrm{PI}$ in the circulations of all groups. Significantly higher ratios of $5 \alpha-$ PIC to $5 \alpha$-PI found in P compared with F and L groups indicate the more intensive conjugation of $5 \alpha$-PI in pregnancy, including that of the most abundant neuroinhibiting steroid P3 $\alpha 5 \alpha$. This mechanism probably provides for the elimination of excessive amounts of neuroinhibiting $\mathrm{P} 3 \alpha 5 \alpha$ in the maternal compartment. The opposite situation was observed in P3 $25 \beta$. This result points to a limited sulfation capacity for pregnanolone in pregnant women. In contrast to the situation in men and non-pregnant women, where the $\mathrm{P} 3 \alpha 5 \beta \mathrm{C}$ is the most abundant PIC but $\mathrm{P} 3 \alpha 5 \beta$ is a minor substance compared with the remaining PI, P3 $\alpha 5 \beta$ may acquire physiological importance in pregnancy, contributing to the sustaining thereof. Quite the opposite effect, the declining formation of $\mathrm{P} 3 \alpha 5 \beta$ as reported recently (Gilbert Evans et al. 2005, Sheehan et al. 2005), may participate in the initiation of human parturition, given relative abundance of the steroid, its potency to suppress the activity of oxytocin-producing cells (Leng \& Russell 1999, Brussaard et al. 2000, Koksma et al. 2003) and its effectiveness in uterine relaxation (Mitchell et al. 2005).

\section{Acknowledgements}

The excellent technical assistance of Mrs Ivona Králová and Mrs Marta Velíková is gratefully acknowledged. The authors declare that there is no conflict of interest that would prejudice the impartiality of this scientific work.

\section{Funding}

This study was supported by Grant Agency of the Czech Republic grant no. 303/04/1086.

\section{References}

Backstrom T, Andersson A, Andree L, Birzniece V, Bixo M, Bjorn I, Haage D, Isaksson M, Johansson IM, Lindblad C et al. 2003 Pathogenesis in menstrual cycle-linked CNS disorders. Annals of New York Academy of Sciences 1007 42-53.

Bixo M, Andersson A, Winblad B, Purdy RH \& Backstrom T 1997 Progesterone, 5alpha-pregnane-3,20-dione and 3alpha-hydroxy-5alphapregnane-20-one in specific regions of the human female brain in different endocrine states. Brain Research 764 173-178.

Brussaard AB, Kits KS, Baker RE, Willems WP, Leyting-Vermeulen JW, Voorn P, Smit AB, Bicknell RJ \& Herbison AE 1997 Plasticity in fast synaptic inhibition of adult oxytocin neurons caused by switch in GABA(A) receptor subunit expression. Neuron 19 1103-1114.

Brussaard AB, Wossink J, Lodder JC \& Kits KS 2000 Progesterone-metabolite prevents protein kinase $\mathrm{C}$-dependent modulation of gamma-aminobutyric acid type A receptors in oxytocin neurons. PNAS 97 3625-3630.

Carl P, Hogskilde S, Lang-Jensen T, Bach V, Jacobsen J, Sorensen MB, Gralls M \& Widlund L 1994 Pharmacokinetics and pharmacodynamics of eltanolone (pregnanolone), a new steroid intravenous anaesthetic, in humans. Acta Anaesthesiologica Scandinavica 38 734-741.

Condon JC, Jeyasuria P, Faust JM \& Mendelson CR 2004 Surfactant protein secreted by the maturing mouse fetal lung acts as a hormone that signals the initiation of parturition. PNAS 101 4978-4983.

Corpechot C, Collins BE, Carey MP, Tsouros A, Robel P \& Fry JP 1997 Brain neurosteroids during the mouse oestrous cycle. Brain Research 766 276-280.

Darnaudery M, Pallares M, Bouyer JJ, Le Moal M \& Mayo W 1999 Infusion of neurosteroids into the rat nucleus basalis affects paradoxical sleep in accordance with their memory modulating properties. Neuroscience 92 583-588.

Dehennin L, Lafarge P, Dailly P, Bailloux D \& Lafarge JP 1996 Combined profile of androgen glucuro- and sulfoconjugates in post-competition urine of sportsmen: a simple screening procedure using gas chromatography-mass spectrometry. Journal of Chromatography. B, Biomedical Applications 687 85-91.

Dombroski RA, Casey ML \& MacDonald PC 1997 5-Alpha-dihydroprogesterone formation in human placenta from 5 alpha-pregnan-3beta/alphaol-20-ones and 5-pregnan-3beta-yl-20-one sulfate. Journal of Steroid Biochemical Molecular Biology 63 155-163.

Genazzani AR, Petraglia F, Bernardi F, Casarosa E, Salvestroni C, Tonetti A, Nappi RE, Luisi S, Palumbo M, Purdy RH et al. 1998 Circulating levels of allopregnanolone in humans: gender, age, and endocrine influences. Journal of Clinical Endocrinology and Metabolism 83 2099-2103.

Gilbert Evans SE, Ross LE, Sellers EM, Purdy RH \& Romach MK 2005 3Alpha-reduced neuroactive steroids and their precursors during pregnancy and the postpartum period. Gynecological Endocrinology 21 268-279.

Havlikova H, Hill M, Kancheva L, Vrbikova J, Pouzar V, Cerny I, Kancheva R \& Starka L 2006 Serum profiles of free and conjugated neuroactive pregnanolone isomers in non-pregnant women of fertile age. Journal of Clinical Endocrinology 91 3092-3099.

Hering WJ, Ihmsen H, Langer H, Uhrlau C, Dinkel M, Geisslinger G \& Schuttler J 1996 Pharmacokinetic-pharmacodynamic modeling of the new steroid hypnotic eltanolone in healthy volunteers. Anesthesiology 85 1290-1299.

Hill M, Parizek A, Bicikova M, Havlikova H, Klak J, Fait T, Cibula D, Hampl R, Cegan A, Sulcova J et al. 2000 Neuroactive steroids, their precursors, and polar conjugates during parturition and postpartum in maternal and umbilical blood: 1. Identification and simultaneous determination of pregnanolone isomers. Journal of Steroid Biochemical Molecular Biology 75 237-244.

Ingelman-Sundberg M 1976 Specific reductive metabolism of steroid sulphates in rat liver. Biochimica et Biophysic Acta 431 592-602. 
Koksma JJ, van Kesteren RE, Rosahl TW, Zwart R, Smit AB, Luddens H \& Brussaard AB 2003 Oxytocin regulates neurosteroid modulation of GABA(A) receptors in supraoptic nucleus around parturition. Journal of Neuroscience 23 788-797.

Leng G \& Russell JA 199 Coming to term with GABA. Journal of Physiology $516(\mathrm{Pt}$ 2) VI.

Lisboa BP \& Holtermann M 1976 Metabolism of 20beta-hydroxy-4pregnen-3-one in uterine tissue of non-pregnant rats in vitro. Acta Endocrinologica 83 604-620.

Luisi S, Petraglia F, Benedetto C, Nappi RE, Bernardi F, Fadalti M, Reis FM, Luisi M \& Genazzani AR 2000 Serum allopregnanolone levels in pregnant women: changes during pregnancy, at delivery, and in hypertensive patients. Journal of Clinical Endocrinology and Metabolism 85 2429-2433.

Lundgren P, Stromberg J, Backstrom T \& Wang M 2003 Allopregnanolonestimulated GABA-mediated chloride ion flux is inhibited by 3betahydroxy-5alpha-pregnan-20-one (isoallopregnanolone). Brain Research 982 45-53.

Majewska MD 1990 Steroid regulation of the GABAA receptor: ligand binding, chloride transport and behaviour. Ciba Foundation Symposia 153 83-97.

Mathur RS, Landgrebe S \& Williamson HO 1980 Progesterone, 17-hydroxyprogesterone, estradiol, and estriol in late pregnancy and labor. American Journal of Obstetrics and Gynaecology 136 25-27.

McLean M \& Smith R 2001 Corticotrophin-releasing hormone and human parturition. Reproduction 121 493-501.

Melcangi RC, Celotti F \& Martini L 1994 Progesterone 5-alpha-reduction in neuronal and in different types of glial cell cultures: type 1 and 2 astrocytes and oligodendrocytes. Brain Research 639 202-206.

Mesiano S 2004 Myometrial progesterone responsiveness and the control of human parturition. Journal of the Society for Gynecologic Investigation 11 193-202.

Mickan H \& Zander J 1979 Pregnanolones, pregnenolone and progesterone in the human feto-placental circulation at term of pregnancy. Journal of Steroid Biochemistry 11 1461-1466.

Milewich L, Gant NF, Schwarz BE, Chen GT \& MacDonald PC 1979 5 alpha-Reductase activity in human placenta. American Journal of Obstetrics and Gynaecology 133 611-617.

Mitchell BF, Mitchell JM, Chowdhury J, Tougas M, Engelen SM, Senff N, Heijnen I, Moore JT, Goodwin B, Wong S et al. 2005 Metabolites of progesterone and the pregnane $\mathrm{X}$ receptor: a novel pathway regulating uterine contractility in pregnancy? American Journal of Obstetrics and Gynaecology 192 1304-1313 (discussion 1313-1305).

Nathanielsz PW 1998 Comparative studies on the initiation of labor. European Journal of Obstetrics and Gynaecology and Reproductive Biology 78 127-132.

Okuda A \& Okuda K 1984 Purification and characterization of delta 4-3ketosteroid 5 beta-reductase. Journal Biological Chemistry 259 7519-7524.

Ottander U, Poromaa IS, Bjurulf E, Skytt A, Backstrom T \& Olofsson JI 2005 Allopregnanolone and pregnanolone are produced by the human corpus luteum. Molecular and Cell Biology 239 37-44.

Pak CW \& Curras-Collazo MC 2002 Expression and plasticity of glutamate receptors in the supraoptic nucleus of the hypothalamus. Microscopic Research and Technique 56 92-100.
Park-Chung M, Wu FS, Purdy RH, Malayev AA, Gibbs TT \& Farb DH 1997 Distinct sites for inverse modulation of $\mathrm{N}$-methyl-D-aspartate receptors by sulfated steroids. Molecular Pharmacology 52 1113-1123.

Park-Chung M, Malayev A, Purdy RH, Gibbs TT \& Farb DH 1999 Sulfated and unsulfated steroids modulate gamma-aminobutyric acidA receptor function through distinct sites. Brain Research 830 72-87.

Patel FA, Funder JW \& Challis JR 2003 Mechanism of cortisol/progesterone antagonism in the regulation of 15-hydroxyprostaglandin dehydrogenase activity and messenger ribonucleic acid levels in human chorion and placental trophoblast cells at term. Journal of Clinical Endocrinology and Metabolism 88 2922-2933.

Pearson Murphy BE, Steinberg SI, Hu FY \& Allison CM 2001 Neuroactive ring A-reduced metabolites of progesterone in human plasma during pregnancy: elevated levels of 5 alpha-dihydroprogesterone in depressed patients during the latter half of pregnancy. Journal of Clinical Endocrinology and Metabolism 86 5981-5987.

Prince RJ \& Simmonds MA 19925 Beta-pregnan-3 beta-ol-20-one, a specific antagonist at the neurosteroid site of the GABAA receptorcomplex. Neuroscience Letters 135 273-275.

Putnam CD, Brann DW, Kolbeck RC \& Mahesh VB 1991 Inhibition of uterine contractility by progesterone and progesterone metabolites: mediation by progesterone and gamma amino butyric acidA receptor systems. Biological Reproduction 45 266-272.

Sheehan PM, Rice GE, Moses EK \& Brennecke SP 20055 Betadihydroprogesterone and steroid 5 beta-reductase decrease in association with human parturition at term. Molecular Human Repoduction 11 495-501.

Todorovic SM, Pathirathna S, Brimelow BC, Jagodic MM, Ko SH, Jiang X, Nilsson KR, Zorumski CF, Covey DF \& Jevtovic-Todorovic V 20045 Beta-reduced neuroactive steroids are novel voltage-dependent blockers of T-type $\mathrm{Ca}^{2+}$ channels in rat sensory neurons in vitro and potent peripheral analgesics in vivo. Molecular Pharmacology 66 1223-1235.

Wang M, He Y, Eisenman LN, Fields C, Zeng CM, Mathews J, Benz A, Fu T, Zorumski E, Steinbach JH et al. 20023 Beta -hydroxypregnane steroids are pregnenolone sulfate-like GABA(A) receptor antagonists. Journal of Neuroscience 22 3366-3375.

Weaver CE, Land MB, Purdy RH, Richards KG, Gibbs TT \& Farb DH 2000 Geometry and charge determine pharmacological effects of steroids on $\mathrm{N}$-methyl-D-aspartate receptor-induced $\mathrm{Ca}(2+)$ accumulation and cell death. Journal of Pharmacological and Experimental Therapeutics 293 747-754.

Wu WX, Ma XH, Coksaygan T, Chakrabarty K, Collins V, Rose J \& Nathanielsz PW 2004 Prostaglandin mediates premature delivery in pregnant sheep induced by estradiol at 121 days of gestational age. Endocrinology 145 1444-1452.

Received in final form 27 June 2007

Accepted 10 July 2007

Made available online as an Accepted Preprint

11 July 2007 